\title{
RESPEITO AOS QUADRINHOS: O CASO TINA
}

\author{
RESPECT FOR COMICS: THE TINA CASE
}

RESPETO POR LOS CÓMICS: EL CASO TINA

\author{
Claudia Regina Lemes ${ }^{1}$ \\ Paulo Roxo Barja ${ }^{2}$
}

Resumo: O presente trabalho tem por objetivo analisar aspectos educativos não formais da HQ "Tina - Respeito", de Fefê Torquato (2019). A obra denuncia a hierarquia coorporativa machista ao apresentar o problema do assédio sexual sofrido por Tina no início de sua vida profissional.

Palavras-chave: Histórias em quadrinhos; assédio sexual; machismo estrutural.

Abstract: This paper aims to analyze non-formal educational aspects of the comic book "Tina Respect", by Fefê Torquato (2019). The work denounces the macho corporate hierarchy by presenting the problem of sexual harassment suffered by Tina at the beginning of her professional life.

Keywords: Comics; sexual harassment; structural machism.

Resumen: Este artículo tiene como objetivo analizar aspectos educativos no formales del cómic "Tina-Respecto", de Fefê Torquato (2019). La obra denuncia la jerarquía corporativa machista al presentar el problema del acoso sexual que sufrió Tina al inicio de su vida profesional.

Palabras clave: Comics; assédio sexual; machismo estrutural.

\section{Introdução}

As histórias em quadrinhos (HQs) são um gênero literário muito lido no Brasil e no mundo. Por longo tempo as HQs foram relegadas à margem da literatura considerada "séria", mas nas últimas décadas ganharam destaque e passaram a ser valorizadas como objeto de estudos acadêmicos, ainda que frequentemente sejam enquadradas na categoria de "entretenimento". Inseridas há décadas no contexto da indústria cultural, as HQs têm inspirado produções em mídias diversas (destacando-se o cinema).

Com o amadurecimento do público e a consolidação da importância econômica do setor, os quadrinhos se sofisticaram e passaram a surgir publicações em formato mais semelhante ao de livros, abordando (direta ou indiretamente) temas sociais e culturais.

No Brasil, o público infantil sempre foi o alvo preferencial das HQs. Nos anos (19)70, a venda era majoritariamente de títulos Disney (Pato Donald, Tio Patinhas e outros), mas desde o final do século XX, as maiores vendas no setor correspondem a criações nacionais, produzidas nos Estúdios Maurício de Sousa (MSP).

O presente trabalho tem por objetivo a análise da produção "Tina - Respeito", obra criada por Fefê Torquato a convite de Maurício de Souza, dentro do selo Graphic MSP, avaliando-se sua efetividade na abordagem do tema do assédio sexual.

\footnotetext{
${ }^{1}$ Instituto de Psicologia (IP) da Universidade de São Paulo (USP).

${ }^{2}$ Universidade do Vale do Paraíba (UNIVAP).
} 


\section{Metodologia}

Para a realização do trabalho, partiu-se de uma leitura inicial da obra, sem preocupação de realização de anotações (leitura para fruição). Após essa primeira leitura, foi efetuada releitura com marcação das passagens-chave da obra. Estas foram então fotografadas e analisadas, sendo posteriormente feita uma seleção das mesmas para inclusão no presente artigo. A análise então efetuada envolveu pesquisa bibliográfica sobre o assunto principal (assédio sexual) abordado pela obra em estudo, bem como sobre indústria cultural, privilegiando-se livros e autores com produção vasta e reconhecida sobre estes temas.

\section{Contexto editorial da obra}

Idealizado na casa editorial da Turma da Mônica, o selo Graphic MSP foi iniciado em 2011 para um projeto comemorativo de 50 anos e já ultrapassa 30 títulos publicados. No selo, artistas convidados tomam como ponto de partida uma das personagens criadas originalmente por Maurício de Souza e a remodelam, inserindo-a num contexto atual e visando principalmente o público jovem e adultos. Nesta perspectiva, a obra em destaque neste artigo tem Tina como personagem principal.

\section{O roteiro}

A narrativa da obra começa revelando que a personagem está no início da vida profissional no jornalismo - momento especial, delicado e cheio de expectativas. Acolhida pelos colegas de trabalho, Tina está ansiosa para conhecer seu provável futuro mentor: trata-se de um profissional experiente e reconhecido no mundo jornalístico.

Ao longo da história, porém, Tina sofre uma grande decepção, à medida que o referido profissional começa a desenvolver atitudes inadequadas em ambiente profissional que acabam por se caracterizar como situação de assédio sexual - problema com o qual muitas mulheres se deparam ainda hoje. A Figura 1, a seguir, mostra uma destas cenas.

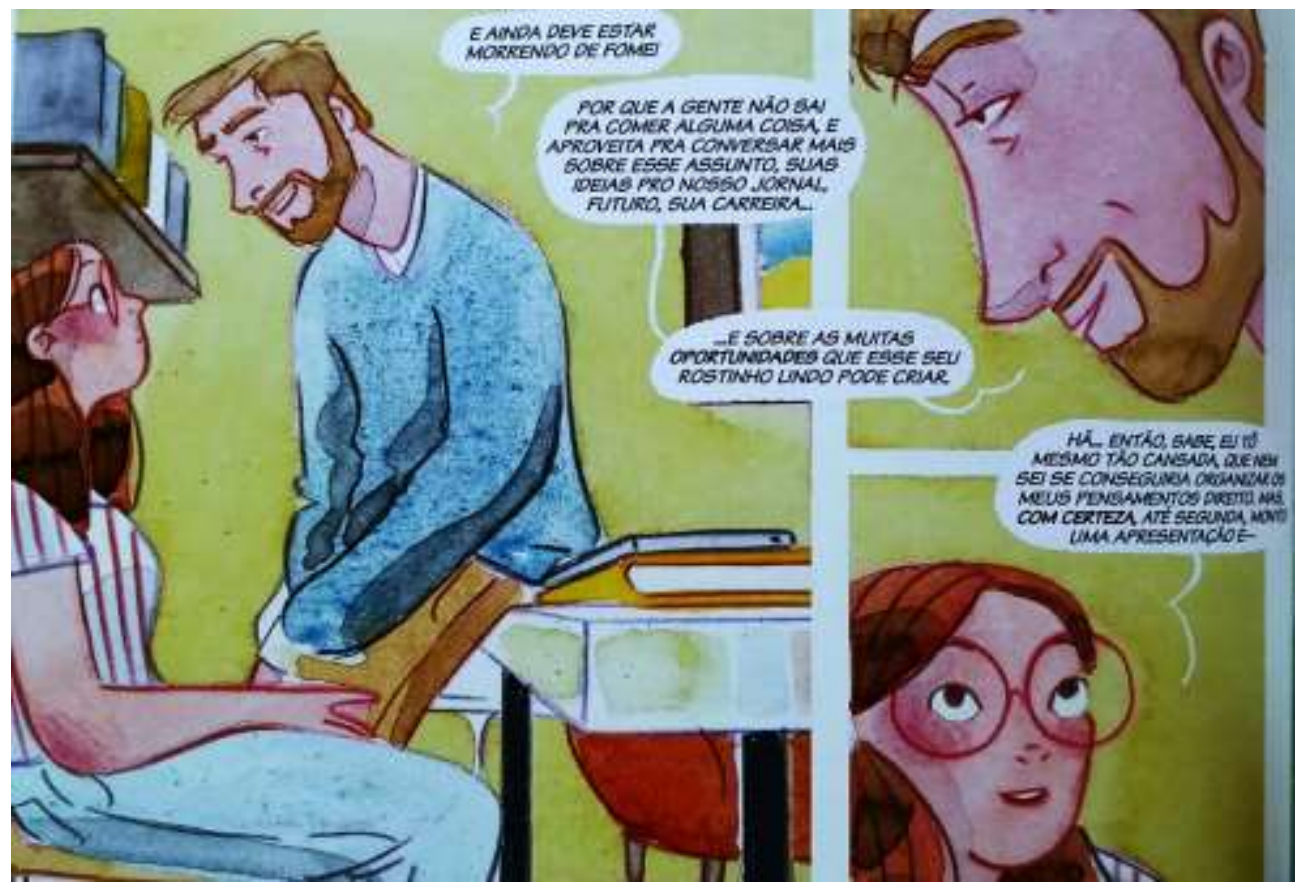

Figura 1: Cena da obra analisada que sinaliza assédio sexual - Fonte: Extraído de TORQUATO (2019, p. 45). 
Neste ponto, Tina enfrenta um dilema: deve denunciar publicamente a pessoa que o assedia? Fazendo isso, não estará colocando em risco seu próprio futuro profissional?

Deste modo, a história contextualiza a insegurança que o assédio provoca nas vítimas e as dificuldades em lidar com tal situação, dadas as tensões surgidas entre:

i. o desejo pessoal de ser bem-sucedida na carreira profissional (obtendo independência financeira);

ii. as exigências de uma sociedade exigem o "sucesso a qualquer custo" no mercado de trabalho;

iii. a cultura machista que gera opressão em diversos meios e camadas sociais, prejudicando a carreira daqueles que se rebelam contra esta situação.

Além do assédio, a história apresenta outras questões, como a presença de diversos tipos de preconceito no ambiente de trabalho e fora dele.

\section{Assédio sexual}

Até 1989, esteve em vigor no Brasil um parágrafo da Consolidação das Leis do Trabalho (CLT), que dava ao marido o direito de pleitear judicialmente a rescisão do contrato de trabalho da mulher se ele entendesse que tal contrato acarretasse ameaça aos vínculos familiares ou perigo manifesto às condições peculiares da mulher (HIGA, 2016).

Historicamente, nas economias pré-capitalistas, a realização pessoal da mulher seria garantida através do casamento. Ou seja: ela dependia de um homem e "[...] através dele é que se consolidava a sua posição social e se garantia a sua estabilidade ou prosperidade econômica" (SAFFIOTTI, 2013, p. 63). A própria existência da mulher era dependente do marido; sua obediência e submissão eram ditadas pela tradição.

No entanto, mesmo nesta sociedade que entendia a mulher jurídica e socialmente como sendo inferior aos homens, ela participava do sistema produtivo e realizava um papel economicamente importante, ainda que na maioria das vezes menos relevante do que o papel desempenhado pelos homens (GUERRA, 2011). Porém, na sociedade capitalista já se prenunciava uma intensificação da marginalização da mulher no processo produtivo:

[...] o processo de sua expulsão do sistema produtivo já está esboçado na forma subsidiária assumida pelo seu trabalho. Tanto na economia feudal, quanto na economia de burgo e sobretudo nesta última, que prepara o advento da economia urbana, fabril, o emprego da força de trabalho feminina encontra sérias barreiras impedindo a penetração das mulheres ou oferecendo-lhes as posições subalternas e menos compensadoras (SAFFIOTTI, 2013, p. 64).

Com o advento do capitalismo, tais condições adversas são apropriadas pelo sistema de produção e a mulher herda as desvantagens sociais já antes dimensionadas no campo mitológico tradicional que encontravam meios para justificativa da supremacia masculina e da ordem social que a gerava. Nesta nova ordem social, a mulher também herdou as desvantagens anteriormente já eram bem delineadas. Como um dos fatores há muito tempo utilizados para justificar a inferiorização e marginalização da mulher na sociedade de classes, o gênero foi usado como justificativa para obstruir a participação da mulher no desenvolvimento social competitivo do novo sistema (SAFFIOTTI, 2013).

Assim, a partir do exposto, a sociedade moderna se estabeleceu organicamente a partir de um pacto fundamentado na diferença entre homens e mulheres que se ancora na suposição de 
que homens são naturalmente superiores, e sendo assim soberanos que podem ter acesso aos corpos das mulheres como se fossem os machos de uma matilha. Para se preservarem neste contexto, a mulher de boa conduta deve esconder o corpo e manter-se discreta. A exibição do corpo equivale a um convite ao acesso destes homens. $\mathrm{O}$ corpo feminino nesta organização social é objetificado como peça do desejo masculino. $\mathrm{O}$ assédio sexual se deve a uma série de fatores, entre eles a postura da sociedade ao encarar a mulher como figura disponível física e moralmente, expondo-a a discriminações brutais. No mercado de trabalho são diversas as circunstâncias complexas que podem acontecer e que envolvem muitas vezes colegas, chefes, patrões e os próprios sindicalistas (UNIÃO..., 2007): "nestas condições, as primeiras reações são de escamotear as ações de constrangimento sexual" (UNIÃO..., 2007, p. 36).

Uma pesquisa do IPEA demonstrou que grande parte da população brasileira atribui à vítima a culpa dos abusos sexuais que ocorrem contra as mulheres, por não se comportarem adequadamente; chegam a argumentar que mulheres que mostram o corpo merecem ser atacadas (IPEA, 2014). O cerne deste tipo de pensamento advém de estruturas antigas que possuem lastros jurídicos, filosóficos e religiosos presentes em quase todas as culturas e que são responsáveis em grande parte pela reprodução dos modelos de relação de poder reproduzidos atualmente; entre elas, as da divisão sexual do trabalho e de relação de gênero que foram construídas ao longo da história. Tais estruturas encarceraram as mulheres em atividades de procriação e funções reprodutivas enquanto os homens encarregados das funções produtivas (HIGA, 2016).

É certo que tais categorias de pensamento, assim como as instituições originadas pelo patriarcado que instaurou o domínio do homem "varão" estão sendo afetadas de forma global (MURARO; BOFF, 2002). As mulheres são as que mais sofrem com as consequências das diferenças entre gêneros presentes nas piadas, assédios, agressões físicas, agressões verbais, comentários grosseiros sobre o corpo e/ou a roupa (TÍLIO et al., 2021).

A ruptura deste paradigma constitui-se como um inconveniente aos alicerces sociopolíticos, o que resulta em acirramentos dos conflitos entre grupos de pensamentos e valores opostos: de um lado, libertários; de outra, grupos conservadores. Neste contexto, os movimentos sociais feministas que deslocam as mulheres da condição de assujeitadas para a de protagonistas de reinvindicações são mal-recebidos pela parcela da sociedade resistente às conquistas e direitos significativos (TÍLIO et al., 2021).

$\mathrm{Na}$ HQ sob análise, a personagem Tina é abordada de modo inadequado em seu trabalho como iniciante na carreira de jornalista, conforme vemos na Figura 2. 


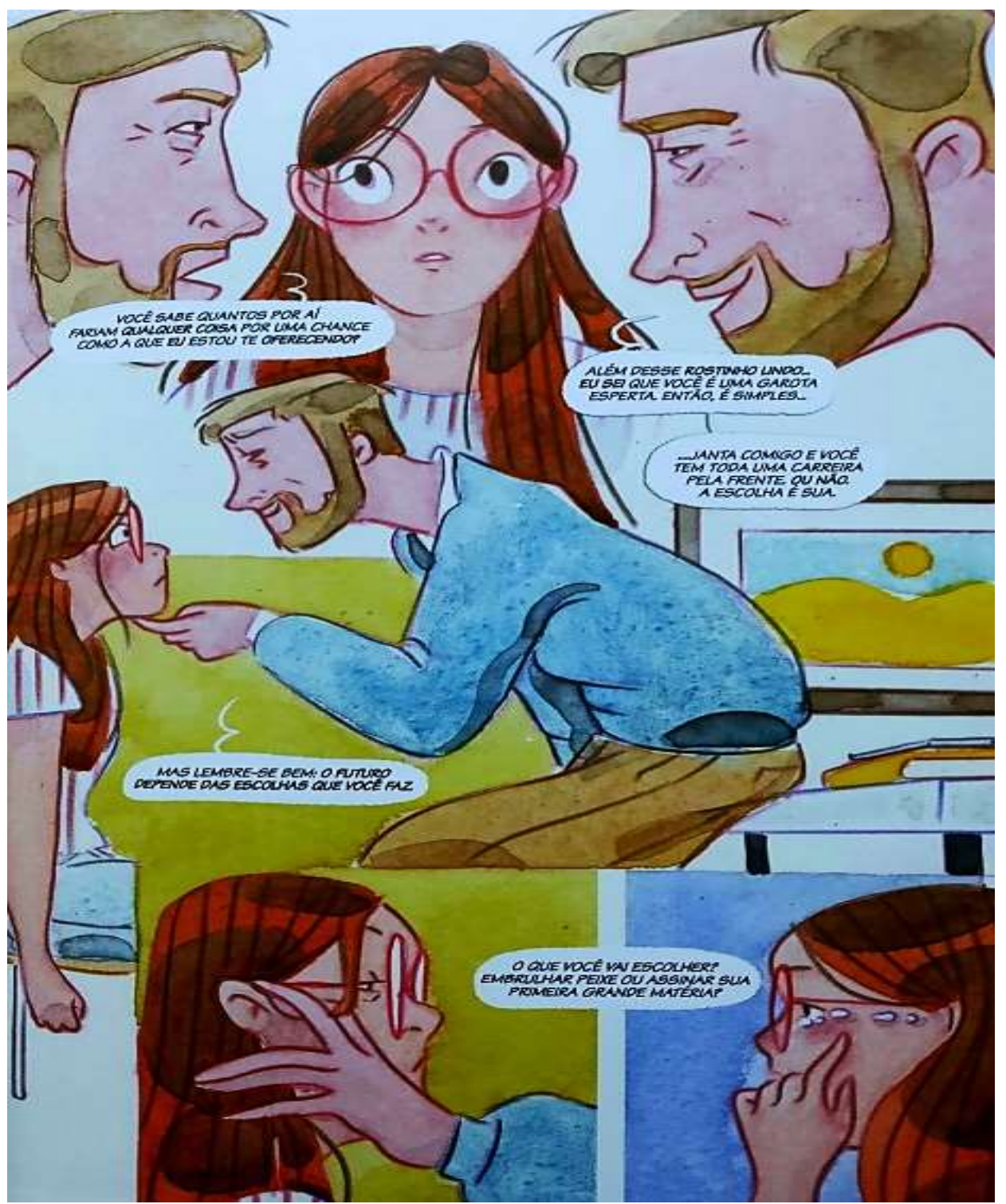

Figura 2: Mais uma cena de assédio sexual na obra sob análise - Fonte: Extraído de TORQUATO (2019, p. 59)

\section{Potencial educativo não formal da HQ}

Em seus estudos sobre a reprodutibilidade técnica, Benjamin (1997) defendeu a alternância entre o agir e o escrever cultivada nas formas literárias modestas para comunidades ativas, em contraposição as molduras literárias que, segundo o autor, eram motivo de infertilidade técnica editorial início do século XX: "Só esta linguagem de prontidão mostra-se atuante à altura do momento" (BENJAMIN, 1997, p. 11).

Atento às demandas do tempo do seu tempo, Benjamin já prenunciava um potencial literário fora dos padrões até então praticados, antes da existência das HQs. Os quadrinhos são hoje fundamentais como prática literária e cultural (GOMES, 2021), de caráter ativo, antecipado já no século XIX a partir de publicações publicitárias sem muitas convenções de tempo e espaço ou mesmo um formato representativo que viria a transformar as experiências leitoras de todo o mundo: a imagem funde-se às letras, formas e cores na construção de significados.

No Brasil, este gênero literário tem se propagado, sendo aproveitado nos espaços do ensino formal em todas as áreas do conhecimento, ainda que não se possa negar a persistência de algum preconceito contra as HQs (PEREIRA; FONTOURA, 2016). 
No entanto, há que se considerar a reflexão freiriana de que a leitura do mundo precede a leitura da palavra e que o ato de ensinar vai muito além da transmissão de conhecimento. As HQs geram possibilidades de construção do conhecimento pelos próprios educandos a partir não só do conteúdo temático, mas também da alternância entre o agir e o escrever que advém de comunidades ativas e suas influências comunicacionais (BENJAMIN, 1997).

\section{Discussão}

Partindo da leitura crítica da obra, nossa análise permite destacar a relevância da temática social apresentada, levando em conta que as HQs são majoritariamente consumidas por público jovem. Apresentam, portanto, um potencial educativo voltado não necessariamente à educação formal, mas sobretudo como forma literária que pode trazer reflexões advindas das problemáticas sociais com abordagens importantes sobre a vida social cotidiana.

Naturalmente, o aspecto visual nos quadros da HQs é levado em conta na construção de significados. No caso da obra em questão, não só a condução dos temas no roteiro como também a própria apresentação gráfica da obra, que utilizou o formato de aquarelas, trouxe leveza, suscitando no observador um olhar mais aprofundado para as questões abordadas. A fusão entre texto e arte contribui assim para que a obra tenha um potencial formativo. Prova disso é que a obra foi recentemente destacada em outro artigo acadêmico, onde Lemes (2021) enfatiza o fato de que a produção exemplifica a presença das mulheres também como criadoras no universo das histórias de quadrinhos.

As HQs têm indiscutivelmente validade formativa no que se refere ao despertar do hábito da leitura; além disso, revelam-se também ferramentas capazes de suscitar percepções da realidade, emocionar, informar e produzir conhecimento a partir de processos cognitivos e criativos (VIGOTSKI, 1988).

\section{Considerações finais}

A análise crítica da obra em questão permite concluir que sua realização pode ser considerada bem-sucedida ao partir do universo tradicional dos quadrinhos brasileiros para apresentar um caráter de inovação tanto no tema quanto na forma de apresentação. As histórias em quadrinhos podem ser uma excelente forma de se despertar crianças, jovens e adultos para a necessidade de debater temas sociais da atualidade, ainda que polêmicos. Ressaltamos que a sociedade contemporânea é composta de mudanças rápidas e intensas e que a todo tempo emergem informações de um mundo letrado em que o ato de ler é imprescindível para se aprender a pensar. Neste sentido, obras como a abordada neste artigo apresentam múltiplo potencial formativo.

\section{Referências}

BENJAMIN, Walter. Rua de mão única. 2. ed. Rio de Janeiro: Paz e Terra, 1997.

GOMES, Ivan Lima. Leitores e leituras de revistas em quadrinhos: uma história visual (anos 1930-1950). Revista Estudos Históricos, Rio de Janeiro, v. 34, n. 72, p. 54-80, jan.-abr. 2021. Disponível em: https://doi.org/10.1590/S2178-149420210104. Acesso em: 21 dez. 2021.

GUERRA, Raquel Diniz. Mulher e discriminação. Belo Horizonte: Fórum, 2011. 
HIGA, Flávio da Costa. Assédio sexual no trabalho e discriminação de gênero: duas faces da mesma moeda? Revista Direito GV, São Paulo, v. 12, n. 2, p. 484-515, maio-ago. 2016. Disponível em: https://doi.org/10.1590/2317-6172201620. Acesso em: 02 nov. 2021.

INSTITUTO DE PESQUISA ECONÔMICA APLICADA - IPEA. Sistema de Indicadores de Percepção Social - SIPS, 2014. Disponível em: http://ipea.gov.br/portal/images/stories/PDFs/SIPS/140327_sips_violencia_mulheres.pdf.

Acesso em: 01 nov. 2021.

LEMES, Cristiane de Andrade. Feminismo, Mulheres e Quadrinhos: Feminismo dentro do quadrinho "Tina-Respeito" de Fefê Torquato. In: SEMINÁRIO INTERNACIONAL DE PESQUISAS EM MÍDIA E COTIDIANO, 8., 2021, on line. Anais... p. 592-600, 2021. Disponível em: http://designnaleitura.net.br/8sipmc/files/gt4_060_18073.pdf. Acesso em: 28 dez. 2021.

MURARO, Rose Marie; BOFF, Leonardo. Feminino e masculino: uma nova consciência para o encontro das diferenças. Rio de Janeiro: Sextante, 2002.

PEREIRA, Elienae Genésia Corrêa; FONTOURA, Helena Amaral da. Discutindo as histórias em quadrinhos enquanto recurso didático em Ciências. Revista Práxis, ano VIII, n. 15, p. 93-104, jun. 2016. Disponível em: https://revistas.unifoa.edu.br/praxis/article/view/670. Acesso em: 28 dez. 2021.

SAFFIOTTI, Heleieth I. B. A mulher na sociedade de classes. 3. ed. São Paulo: Expressão Popular, 2013.

TÍLIO, Rafael de; MORÉ, Isabella Alves Azevedo; SAMPAIO, Natália Prado; RIBEIROLEANDRO, Renata Cristina; COHEN, Carla Cristina; LEÔNIDAS, Carolina. Corpo feminino e violência de gênero: uma análise do documentário "chega de fiu fiu". Psicologia \& Sociedade, n. 33, p. 1-16, e228620, 2020. Disponível em: https://www.scielo.br/j/psoc/a/wWtLhjQP3hRQC5hDt6Pz7qq/?lang=pt\&format=pdf.

Acesso em: 27 dez. 2021.

TORQUATO, Fefê. Tina: respeito. São Paulo: Panini, 2019.

UNIÃO das Mulheres de São Paulo. Violência contra a mulher e a impunidade: uma questão política. São Paulo: UMSP, 2007.

VIGOTSKI, Lev Semenovich. A formação social da mente. São Paulo: Martins Fontes, 1988.

\section{Sobre os autores}

Claudia Regina Lemes. Doutoranda pelo Instituto de Psicologia da Universidade de São Paulo. Mestre em Semiótica, Tecnologias de Informação e Educação pela Universidade Braz Cubas (2009). MBA em Gestão Empresarial e Educação pela Universidade Federal Fluminense (2016). Pós Graduação em Psicopedagogia (2021). Professora na Secretaria Estadual de Educação de São Paulo.

E-mail: claurlemes@gmail.com. 
Paulo Roxo Barja. Doutor em Ciências (Unicamp), com pós doutorado pela ESALq/USP. Autor de 15 livros na área de literatura, desde 2002 é docente-pesquisador na Universidade do Vale do Paraíba (UNIVAP).

E-mail: prbarja@gmail.com. 